to problemático" de Hartmann y, más concretamente, de la tópica de Viehweg y de lo que llama "pensamiento comparativo", como alternativas al uso de la lógica deductiva. En esta parte vuelven a manifestarse las limitaciones de la obra debidas a su carácter de texto elemental para estudiantes que se inician en la filosofía del derecho. Claro está que, por otro lado, es bajo esta perspectiva como más conviene enfocar la obra, con lo cual, el juicio será más favorable. En relación con la primera edición se advierte que el autor ha recibido algunas influencias de la que en términos muy generales podríamos llamar filosofía analítica: asi lo muestran las referencias a Schlick, Popper, Kraft, Stegmüller, autores de habla alemana; y a Hare, Hart, Moore y Rawls, de habla inglesa. Esperamos que en las sucesivas ediciones, o quizás en otra obra, Zippe. luis profundice en la confrontación con la filosofía analítica, que recientemente ha tomado direcciones convergentes con la filosofía clásica alemana en la que se formó el autor.

\section{JAVIER EsQUIVEL}

G. W. F. Hegel, Lecciones sobre historia de la filosofía, traducción de Wenceslao Roces, edición preparada por Elsa Cecilia Frost; Fondo de Cultura Económica, México, tres volúmenes; primera reimpresión, 1977, 839 pp.

La primera edición alemana de este libro apareció en 1833, dos años después de la muerte del filósofo. La primera edición española - de la cual es reim. presión la actual— es de 1955 y sigue la segunda versión alemana (1844), corregida y aumentada. Como suele suceder con los libros póstumos de Hegel - todos ellos basados en lecciones - se trata de una obra mucho más clara que las que el autor publicó en el curso de vida. Se trata, por otra parte, de una obra fundamental. De ahí que se comente ahora esta segunda impresión en castellano.

Obra fundamental por lo menos en dos sentidos: dentro de la obra misma de Hegel y como parte integrante de ella; como sintoma e indicio de la filiación misma de la filosofía de Hegel. El primer punto es sencillo. Hegel pensaba que su filosofía era la síntesis de la totalidad de la filosofía y que, en su sistema, las filosofías del pasado venían a organizarse de tal manera que formaban un sistema total: el de Hegel. El segundo punto es, a mi modo de ver, de mayor interés. La atracción de Hegel hacia tal o cual filósofo viene a iluminar la posición del propio Hegel, no siempre clara en sí misma. ¿Quiere esto decir que Hegel lleva únicamente agua a su molino y que no sabe ver a los filó. sofos del pasado con "objetividad"? No es el caso: Hegel es un gran cono. cedor de la historia de la filosofía como lo fue también sin duda - y más de lo que a veces se piensa - de la historia. No se trata, en una breve nota, de señalar todos los filósofos por los cuales Hegel siente cierta preferencia. Recordemos, solamente de paso, que Hegel en. cuentra en Heráclito las raíces de la dialéctica, que ve en Anaxágoras al pri. mer filósofo del Espíritu (el mismo Es. píritu que Hegel analizará en la $F$ enomenología o aun en la Lógica), que define a Dios como Aristóteles ("pensa. miento del pensamiento" limitado en Aristóteles e infinito en Hegel), que se acerca al monismo de Proclo más que 
al de Plotino, a quien, por cierto, no considera un místico. ¿Cuál será el filósofo más sintomático para entender la filosofía propia de Hegel? Se trata más de un místico que de un filósofo: de Jacobo Böhme.

A primera vista, la relación entre Hegel y Böhme no puede parecer sino paradójica. ¿Qué hay en común entre el místico zapatero y el filósofo de la razón que fue o, mejor, quiso ser Hegel?

Para contestar a esta pregunta es necesario precisar hasta que punto Hegel fue lo que quiso ser: un racionalista. De hecho, su visión de la realidad lo condujo a una suerte de filosofía mística que Hegel quiso hacer racional. Esta afirmación no es gratuita. En algunos de los escritos de juventud $\longrightarrow$ que pronto publicará completos el Fondo de Cultura Económica- Hegel muestra su inclinación místico-religiosa y propone una filosofia del amor. Naturalmente, lo que Hegel pensó en su juventud no es necesariamente lo que Hegel pensó en su madurez. Con todo, su acercamiento al absoluto -por los caminos sucesivos del arte, la religión y la filosofía- lo convierte en un pensador que trató de ra. cionalizar al absoluto y que, en realidad, tuvo que "metaforizarlo". Nada tengo contra ell uso de las metáforas. Pero el caso es que Hegel, quien niega el lenguaje figurado como lenguaje filosófico, emplea este mismo lenguaje figurado que, precisamente, emplean con frecuencia los místicos y los poetas. Lo que unió a Hegel y a Hölderlin fue una honda amistad y también una verdadera vocación poética que se pone de manifiesto en un poema nada malo que, con el título de Eleusis, dedicó a Hölderlin en 1796 (poema, por otra parte que muestra a Hegel como el romántico que fue). Pero volvamos a la relación Böhme-Hegel. En realidad
Böhme es "la primera figura en quien la filosofía alemana se manifiesta con su carácter propio y peculiar" (vol. III, p. 229). Hay que defender a Böhme. ¿Es solamente un soñador? Supongamos que lo fuera: "el calificativo ... podría aplicarse a cualquier filósofo, incluso a un Epicuro y a un Bacon, ya que tam. bién estos opinaban que el hombre debía buscar su verdad en algo que no fuese simplemente comer y beber". La defensa es débil (el comer y el beber no son lo mismo para Bacon que para Blake -a quien Hegel pudo haber mencionado). Es débil pero es revelador: Hegel se empeña en hacer de Böhme su filósofo. Dicho sea parentéticamente, también Leibniz profesó una especial admiración por Böhme: ¿será porque Leibniz estuvo tan cerca de filosofías ocultas y herméticas?, ¿habría que tra. zar una línea de hermetismo que iría de Böhme a Hegel a través de Leibniz? La hipótesis es tentadora. No voy a lan. zarme, sin embargo, a indagarla. Quisie$\mathrm{ra}$, con todo, indicar que muchos de los pensadores herméticos pretenden encon. trar las relaciones secretas entre las co. sas. Y en muchos sentidos Hegel - tam. bién Leibniz - afirma que el universo es relacional y pretende desentra. nar el sentido de las relaciones silencio. sas y presentes que existen en el universo. Pero volvamos a Böhme visto por Hegel. ¿Por qué afirma Hegel que el místico zapatero es el primer filósofo de una filosofía propiamente alemana? Se trata de un filósofo "bárbaro"; y si Böhme es "bárbaro" lo es, especialmente, por su empleo de un lenguaje no filosófico, de un lenguaje "figurado". En realidad Böhme establece un sistema trinitario en el cual hay que sobrepasar las contradicciones para alcanzar la uni. dad. Sus ideas fundamentales pueden resumirse, según Hegel, en este breve pá. 
rrafo: "a) el alumbramiento de la luz, como el Hijo de Dios, a base de las cualidades por la más viva dialéctica; $b$ ) la refración de Dios con respecto a sí mismo". Esto es lo que piensa Böhme "sin concepto". Es lo que pensará Hegel "con concepto" porque, más de una vez, Hegel insiste en que su sistema es trinitario y que los tres grandes movimientos de su filosofía representan - como en Böhme- al Padre, al Hijo y al Espíritu. Por otra parte el Ser de la Lógica hegeliana se asemeja a un primer "alumbramiento" de la misma manera que ( ¿más cercano a Böhme que a Aris. tóteles?) Hegel ve a Dios -mejor dicho, a este Dios racional que es la Idea- como autorreflexión.

¿"Bárbaro" Böhme porque procede sin concepto? La pregunta remite a otra: ¿Lógico Hegel porque predomina en él el "concepto"?

Antes de responder a esta pregunta hay que recordar que la palabra "concepto" traduce mal el "Begriff" alemán, mucho más lleno de "vitalidad" que el pensar puramente conceptual. Hay que notar, por otra parte, que Hegel intenta un sistema racional y que en su obra brilla, a pesar de los pesares, una clari. dad que no se encuentra en los escritos "teosóficos" de Böhme. Sin embargo, cuando Hegel quiere referirse a la realidad más alta -el Espíritu-, cuando precisamente debería emplear un lengua. je más racional, se ve obligado a emplear el lenguaje figurativo y "bárbaro" que atribuía a Böhme. Los ejemplos abundan. Basten aquí tan sólo dos, ambos de la última página de la $F$ enomenología del Espiritu. Escribe Hegel en un lenguaje figurado: "La meta, el saber absoluto o el espíritu que se sabe a sí mismo como espíritu tiene como su camino el recuerdo de los espíritus como son en ellos mismos y como llevan a cabo la organización de su reino." ¿No es figurativo este lenguaje?; ¿dónde esta aquí el concepto? Unas líneas más adelante termina la Fenomenología. De la misma manera que Aristóteles tiene que terminar el libro XII de la Metafísica con unos versos homéricos, Hegel se ve obligado a cerrar su libro con unos versos de Schiller apenas modificados:

\section{del cáliz de los espiritus rebosa para él su infinitud.}

Nuevamente el lenguaje metafórico. Lo cual no importaría si Hegel no hu. biera negado antes la posibilidad misma de una filosofía, por así decirlo, figurada. ${ }_{\text {¿Hegel místico? No es seguro. Lo }}$ que es seguro es que tiene que emplear el lenguaje de los poetas -igual que Böhme- cuando alcanza los niveles que Hegel deseaba absolutamente racionales.

Es probable que la relación BöhmeHegel, establecida por Hegel mismo, revele aspectos de una filosofía mucho menos conceptual de lo que pretendió ser y mucho más cercana al poema Eleusis de lo que sospechó ser.

Esta reseña es injusta. Lo es porque el tema que aqui he desarrollado no es el único dentro de una obra vasta y llena de fuerza creadora. ¿Falla principal, desde un punto de vista objetivo? La brevísima referencia a la filosofía de la Edad Media. Interés especialísimo: la polémica que Hegel entabla con sus predecesores - Descartes, Malebranche, Kant- y sobre todo sus contemporáneos: Fichte y Schelling. Pero, y fundamentalmente, un libro esencial para entender a quien lo escribió: a Hegel mismo.

Ramón Xirau 